\title{
Growth performance, carcass traits and histological changes in the intestinal villi of male broiler chickens fed dietary silicic acid powder containing bamboo vinegar liquid
}

\author{
J. Rattanawut ${ }^{1,3}$ and K. Yamauchi ${ }^{2}$ \\ ${ }^{1}$ Prince of Songkla University, Faculty of Science and Industrial Technology, Surat Thani Campus, Surat Thani 84000, Thailand \\ ${ }^{2}$ Kagawa University, Laboratory of Animal Science, Faculty of Agriculture, Miki-cho, Kagawa-ken 761-0795, Japan
}

KEY WORDS: chicken, bamboo vinegar, silicic acid powder, intestinal histology

Received: 4 June 2014

Revised: 19 February 2015

Accepted: 16 March 2015

${ }^{3}$ Corresponding author:

e-mail: jassada.r@psu.ac.th

\begin{abstract}
To evaluate the effects of silicic acid powder containing bamboo vinegar liquid (SPV) on growth performance, carcass traits and intestinal histology, 80 male broilers at 7 days of age were divided into four treatment groups, each with four replicates of five chickens. The birds were fed ad libitum a basal diet supplemented with SPV at a level of $0 \%, 0.1 \%, 0.2 \%$ or $0.3 \%$ until 49 days of age. Body weight gain was the highest in chickens fed the $0.2 \%$ SPV diet. The dietary treatments had no significant effects on performance or carcass traits. Tissue observations by light microscopy revealed that villus height and villus areas of the duodenum and jejunum were comparatively higher in the $0.2 \%$ SPV group. Duodenal and jejunal cell mitosis were also increased by this diet. These results indicate that dietary SPV at $0.2 \%$ could stimulate intestinal functions in broiler chickens.
\end{abstract}

\section{Introduction}

Antibiotics have been widely used in poultry diets to maintain health and production efficiency. However, with bans on the use of antibiotics as growth promoters in animal feed, finding ways to replace them is necessary. Acidifiers are an alternative to antibiotics in poultry for promoting growth and improving gut health. Acidifiers in feed lower the stomach $\mathrm{pH}$, which increases the activity of proteolytic enzymes. This improves protein digestibility and contributes to weight gain of the host animal (Partanen and Mroz, 1999). Furthermore, proliferation of pathogenic and zoonotic bacteria in the feed is inhibited by its acidity, with similar inhibition in the gastrointestinal tract, which is beneficial to animal health. Bamboo vinegar liquid is an acidic byproduct of bamboo charcoal production. The main components of bamboo vinegar are acetic acid and water, which contribute $3.5 \%-4 \%$ and $80 \%-90 \%$, respectively (Velmurugan et al., 2009). The organic compounds in bamboo vinegar are classified into carboxylic acids, phenols, ketones and aldehydes (Akakabe et al., 2006). The acid in wood vinegar enhances the growth of Bifidobacterium and Enterococcus, but inhibits the growth of Salmonella species (Watarai and Tana, 2005). It is reported that bamboo vinegar can act as an insecticide, bactericide and deodorant for treating pet malodour and has been used in folk medicine (Akakabe et al., 2006). Silicic acid is a weak acid and is the active form of silicon in both plants and animals. Silicon (50-500 ppm) is essential for growth and skeletal development in chickens (McDowell, 1992).

Recently, a powder form mixture of silicic acid and bamboo vinegar liquid (SPV) has been produced in Japan for supplementation of animal feeds. The addition of SPV to diets improved the body weight 
gain in lightweight chickens (Ruttanavut et al., 2012). However, there is no prior published study of the effects of SPV in the feed of fast growing chickens. In this study, the effects of dietary SPV on growth performance, carcass traits and intestinal histology were examined in broiler chickens.

\section{Material and methods}

\section{Preparation of SPV}

The commercial SPV (pH 4) used in this study was produced by Shikoku Tekuno Co., Ltd. (Kagawa, Japan) as follows. Bamboo vinegar compound liquid (Table 1), obtained after cooling smoke during the making of bamboo charcoal from moso bamboo (Phyllostachys pubescens) by dry distillation at $700^{\circ} \mathrm{C}$ in an airless condition, was kept for one year. Then, the skimmed solution was distilled to remove harmful substances such as tar. Next, the vinegar compound was adsorbed into commercial silicic acid powder ( 50 mesh particle size) at a mixing ratio of 31 per $5 \mathrm{~kg}$.

\section{Birds, housing and feeding}

All experiments were conducted according to the guidelines for the care and use of laboratory animals established by Kagawa University. Eighty 1-day-old vaccinated (Newcastle disease and infectious bronchitis) male Marshall Chunky broilers were obtained from a local commercial hatchery. The chickens were housed in electrically heated brooder cages under continuous light for one week and provided with ad libitum access to water and a conventional starter mash diet. At 7 days of age, the birds were weighed and randomly divided into 4 treatment groups, each with 4 replicates of 5 birds, the random assignment performed along strata of similar body weight. The birds were housed in an environmentally controlled room with continuous light.

The commercial basal diets (Table 2) were supplemented with SPV at $0 \%, 0.1 \%, 0.2 \%$, or $0.3 \%$ for a total of 4 treatments. The birds were fed a starter

Table 1. Chemical composition of bamboo vinegar liquid ${ }^{1}$

\begin{tabular}{ll}
\hline Item & Composition, $\mathrm{g} \cdot \mathrm{kg}^{-1}$ \\
\hline Total organic content & 113.7 \\
Acetic acid & 28.7 \\
Methanol & 0.7 \\
Formaldehyde & 0.03 \\
Phenol & 1.77 \\
Cresol & 0.43 \\
Tar & 7.3 \\
pH & 3.25 \\
\hline
\end{tabular}

${ }^{1}$ analysed in triplicate samples
Table 2. Feed formulations and chemical compositions of broiler starter and finisher mash diets, $\mathrm{g} \cdot \mathrm{kg}^{-1}$

\begin{tabular}{|c|c|c|}
\hline Indices & $\begin{array}{l}\text { Starter } \\
1 \text { to } 21 \mathrm{~d}\end{array}$ & $\begin{array}{l}\text { Finisher } \\
22 \text { to } 49 \mathrm{~d}\end{array}$ \\
\hline \multicolumn{3}{|l|}{ Ingredient, as-fed basis } \\
\hline maize & 610 & 640 \\
\hline maize gluten meal & 290 & - \\
\hline soyabean meal & - & 270 \\
\hline rice bran & 23 & 52 \\
\hline fish meal & 70 & 30 \\
\hline tallow & 5 & 6 \\
\hline vitamin-mineral mixture ${ }^{1}$ & 2 & 2 \\
\hline \multicolumn{3}{|l|}{ Calculated chemical composition } \\
\hline crude protein & 220 & 180 \\
\hline crude fibre & 40 & 40 \\
\hline crude fat & 40 & 60 \\
\hline $\mathrm{Ca}$ & 10 & 8 \\
\hline$P$ available & 4 & 3 \\
\hline metabolizable energy, $\mathrm{kcal} \cdot \mathrm{kg}^{-1}$ & 3.050 & 3.250 \\
\hline
\end{tabular}

${ }^{1}$ vitamin-mineral mixture included, provided per $\mathrm{kg}$ of diet: IU: vit. $\mathrm{A}$ 9,600 , vit. $D_{3} 1,920$; $\mathrm{mg}$ : vit. $E 35$, vit $K 2.6$, vit. $B_{1} 5.8$, vit. $B_{2} 7.3$, vit. $B_{6} 10.4$, biotin 0.2 , pantothenic acid 16.1 , folic acid 1.0, nicotinic acid 69.1, choline 1,400, zinc 79.9, copper 12.8, manganese 92; $\mu \mathrm{g}$ : vit. $\mathrm{B}_{12} 12.6$

diet until 21 days of age and a finisher diet from 22 to 49 days of age. Feed and water were provided ad libitum. Feed intake, body weight, feed efficiency and mortality rate were recorded weekly and analysed.

\section{Carcass traits}

At 49 days of age, 8 chickens with a similar average body weight were selected from each treatment (two from each replicate group) and killed by decapitation. They were slaughtered by bleeding the jugular vein and their feathers were plucked. Heads, viscera and shanks were removed. The carcass was left for $1 \mathrm{~h}$ to remove excess water and then weighed. The organs were carefully excised. The breast meat, abdominal fat, liver, gizzard and heart were removed, weighed and their weights recorded relative to body weight.

\section{Tissue sampling and preparation}

At the end of the feeding experiment, 4 birds having the mean body weight of the group were used from each group for histological observations of the villi in each intestinal segment. After decapitation, the entire small intestine was excised and fixed in a mixture of 3\% glutaraldehyde and 4\% paraformaldehyde fixative solution ( $\mathrm{pH}$ 7.4). Tissue samples from the middle of the duodenum, jejunum, and ileum of the small intestine were cut into $20 \mathrm{~mm}$ sections, kept in Bouin's fixative solution, dehydrated in an alcohol series and then embedded in paraffin. Each section was further cut to $4 \mu \mathrm{m}$-thick 
sections and fixed on glass slides. The samples were stained with hematoxylin and eosin, covered with coverslips and examined. Villus height, villus area and cell mitosis counts were determined using an image analyzer (Nikon Cosmozone IzS, Nikon Co., Ltd., Tokyo, Japan) connected to a light microscope. The villus height was measured from the villus tip to the bottom, excluding the crypt. A total of 16 villi were examined from different sections in each bird. The villus area was calculated from the villus height, basal width and apical width and a total of 16 villus areas were calculated for each bird. The counts of mitotic cells having homogeneous, strongly-stained basophilic nuclei were determined. The total cell mitotic number was counted from 4 different sections for each bird and all mitotic cells in each section were counted. The mean values from 4 birds in each treatment are given as the means of mitotic cell counts.

\section{Statistical analysis}

All data were statistically analysed using oneway ANOVA, and significant differences between treatments were determined with Duncan's multiple range test using the SAS program (SAS Institute Inc. Cary, NC, 2003) at a level of $P<0.05$.

\section{Results}

Feed intake, body weight gain and feed efficiency were not significantly different among the groups, although body weight gain and feed efficiency showed slightly higher values in chickens fed the $0.2 \%$ SPV diet (Table 3 ). The birds remained healthy and no significant mortality was observed during the experimental period.

The level of supplemental SPV did not affect dressed carcass, breast meat, abdominal fat, liver, gizzard and heart weight (Table 4).

Table 3. Effects of silicic acid powder containing bamboo vinegar liquid (SPV) on growth performance in broiler chickens during 7 to 49 days of age

\begin{tabular}{lllllll}
\hline Indices & \multicolumn{3}{l}{ Dietary SPV, \% } & & SEM & $P$ \\
\cline { 2 - 6 } & 0 & 0.1 & 0.2 & 0.3 & & \\
\hline Feed intake, kg & 5.899 & 5.856 & 5.845 & 5.883 & 0.052 & 0.987 \\
$\begin{array}{c}\text { Initial body } \\
\text { weight, kg }\end{array}$ & 0.148 & 0.147 & 0.148 & 0.149 & 0.002 & 0.990 \\
$\begin{array}{c}\text { Final body } \\
\text { weight, kg }\end{array}$ & 3.324 & 3.297 & 3.415 & 3.303 & 0.037 & 0.701 \\
$\begin{array}{c}\text { Body weight } \\
\text { gain, } \mathrm{kg}\end{array}$ & 3.176 & 3.150 & 3.267 & 3.154 & 0.036 & 0.698 \\
$\begin{array}{c}\text { Feed efficiency, } \\
\mathrm{kg} \cdot \mathrm{kg}^{-1}\end{array}$ & 0.538 & 0.537 & 0.559 & 0.536 & 0.008 & 0.796 \\
\hline
\end{tabular}

data are means of 4 replicates
Table 4. Effects of silicic acid powder containing bamboo vinegar liquid (SPV) on carcass yield and internal relative organ weight of broilers at 49 days of age

\begin{tabular}{lrrrrrl}
\hline \multirow{2}{*}{ Indices } & \multicolumn{3}{c}{ Dietary SPV, \% } & \multirow{2}{*}{ SEM } & \multirow{2}{*}{$P$} \\
\cline { 2 - 5 } & \multicolumn{1}{c}{0} & 0.1 & 0.2 & 0.3 & & \\
\hline Dressed carcass, \% & 76.25 & 76.40 & 75.82 & 75.15 & 0.25 & 0.304 \\
Breast, \% & 18.03 & 17.92 & 18.57 & 17.65 & 0.27 & 0.724 \\
Abdominal fat, \% & 1.95 & 1.97 & 2.18 & 2.10 & 0.05 & 0.365 \\
Liver, \% & 2.22 & 2.27 & 2.40 & 2.30 & 0.05 & 0.720 \\
Gizzard, \% & 2.05 & 1.98 & 2.10 & 1.95 & 0.04 & 0.635 \\
Heart, \% & 0.68 & 0.70 & 0.69 & 0.66 & 0.02 & 0.874 \\
\hline
\end{tabular}

data are means of 4 replicates; body weight before slaughter $-100 \%$; abdominal fat - abdominal plus visceral fat

Table 5. Villus height, villus area and cell mitosis counts of the duodenum, jejunum and ileum in broilers receiving $0,0.1,0.2$ and $0.3 \%$ dietary silicic acid powder containing bamboo vinegar liquid (SPV)

\begin{tabular}{|c|c|c|c|c|c|c|}
\hline \multirow{2}{*}{ Indices } & \multicolumn{4}{|c|}{ Dietary SPV, \% } & \multirow{2}{*}{ SEM } & \multirow{2}{*}{$P$} \\
\hline & 0 & 0.1 & 0.2 & 0.3 & & \\
\hline \multicolumn{7}{|c|}{ Villus height, mm } \\
\hline duodenum & $1.53^{\mathrm{ab}}$ & $1.51^{b}$ & $1.56^{\mathrm{a}}$ & $1.51^{\mathrm{b}}$ & 0.008 & 0.033 \\
\hline jejunum & $0.93^{b}$ & $0.92^{b}$ & $1.03^{a}$ & $0.91^{b}$ & 0.017 & 0.039 \\
\hline ileum & 0.62 & 0.61 & 0.65 & 0.60 & 0.009 & 0.213 \\
\hline \multicolumn{7}{|c|}{ Villus area, mm² } \\
\hline duodenum & $0.172^{b}$ & $0.170^{b}$ & $0.181^{a}$ & $0.172^{b}$ & 0.001 & 0.047 \\
\hline jejunum & $0.098^{b}$ & $0.100^{b}$ & $0.108^{a}$ & $0.098^{b}$ & 0.001 & 0.039 \\
\hline ileum & 0.060 & 0.061 & 0.062 & 0.059 & 0.001 & 0.071 \\
\hline \multicolumn{7}{|c|}{ Mitotic cell count, No. } \\
\hline duodenum & $820^{\mathrm{ab}}$ & $803^{b}$ & $878^{a}$ & $811^{b}$ & 8.86 & 0.048 \\
\hline jejunum & $615^{b}$ & $624^{b}$ & $658^{a}$ & $604^{b}$ & 6.27 & 0.002 \\
\hline ileum & 492 & 504 & 508 & 490 & 3.08 & 0.074 \\
\hline
\end{tabular}

data are means of 4 replicates; a,b means with different superscripts within a row are significantly different at $P<0.05$

Villus height, villus area and mitotic cell counts of the control and treatment groups are shown in Table 5. Both villus height and area in the duodenum and the jejunum were the highest in birds fed the $0.2 \%$ SPV diet $(P<0.05)$. In the birds fed the $0.2 \% \mathrm{SPV}$ diet, duodenal and jejunal cell mitosis was increased relative to the other treatment groups $(P<0.05)$.

\section{Discussion}

The addition of bamboo vinegar to pig diets has a positive influence on growth performance (Wang et al., 2012). Also, in a previous study the addition of SPV at $0.3 \%$ to diets improved production performance in lightweight chickens (Sanuki Cochin; Ruttanavut et al., 2012). The main purpose of the current study was to investigate the impact of dietary SPV on performance and intestinal histology in fast-growing chickens. These experiments failed to significantly improve body weight gain. Bamboo 
vinegar liquid in the SPV includes more than 200 accessory ingredients, including phenolic compounds, polyphenolic compounds and various organic acids (Kimura et al., 2002). Phenolic compounds are currently receiving much attention because of the putative health effects related to their antioxidant, anticarcinogenic, anti-inflammatory and antimicrobial activities (Viveros et al., 2011). Some phenolic compounds such as resveratrol, hydroxytyrosol, quercetin and several phenolic acids have been reported to inhibit various pathogenic microorganisms (Aziz et al., 1998). Moreover, organic acids in bamboo vinegar reportedly increase gastric proteolysis and improve the digestibility of proteins and amino acids (Samanta et al., 2010). In addition, these acids inhibit the growth of intestinal bacteria which compete with the host animal for available nutrients (Dhawale, 2005). These effects would improve the growth performance of the host. Acetic acid is the main organic acid component in bamboo vinegar. It can control the balance of intestinal microflora and pathogens (Sorrells and Speck, 1970) and affects intestinal functions and metabolism (Lutz and Scharrer, 1991). Alternatively, the silicic acid contained in SPV is a source of the element silicon. Silicon is required for the maximal enzyme activity of prolyl hydroxylase, a determinant of the rate of collagen biosynthesis (Carlisle et al., 1981). However, previous research with supplemental silicon showed no significant effects on the growth performance of broiler chickens when basal diets contained from 0.6 to $143 \mathrm{ppm}$ silicon (Elliot and Edwards, 1991). In our study the birds fed the $0.3 \%$ SPV diet had similar body weight gain to the control birds.

Body weight gain was the highest in the broiler chickens fed the $0.2 \%$ SPV diet. In these birds, intestinal villus height, villus area and cell mitosis counts were highest, both in the duodenum and the jejunum. Increased body weight was associated with an increase in villus height, villus size and cell mitosis in chickens (Ruttanavut et al., 2012). An increased height of the intestinal villi implies a greater surface area for nutrient absorption. Greater villus height and increased cell mitosis counts in the intestine indicate that the function of the intestinal villi was activated (Yamauchi, 2007). Furthermore, an increased villus size is also associated with activated cell proliferation in the crypt (Lauronen et al., 1998), leading to more surface area for nutrient absorption and thus improved nutrient digestibility. Gilmore and Ferretti (2003) found that villus height is increased, with enhanced efficiency of digestion and absorption of the small intestine, due to a popula- tion of beneficial bacteria that supplies nutrients and stimulates vascularization and development of the intestinal villi. Whereas Choct (2009) found a shorter villus with increased counts of pathogenic bacteria in the gastrointestinal tract. Bamboo vinegar reduces the growth of many pathogenic bacteria (Jiang, 2005; Chu et al., 2013). As a result, it may reduce intestinal colonization and slow the infection progression, thereby decreasing inflammatory processes in the intestinal mucosa, which improves villus height and its functions of secretion, digestion and absorption of nutrients. The present results show that $0.2 \% \mathrm{SPV}$ could effectively stimulate intestinal function in the duodenum and jejunum, but there was no significant effect on the ileum. This may be explained by the fact that under normal circumstances the major absorption of nutrients occurs in the duodenum and jejunum (Noy and Sklan, 1995).

\section{Conclusions}

In conclusion, $0.2 \%$ dietary silicic acid powder containing bamboo vinegar liquid stimulated the function of villi in the duodenum and jejunum, resulting in a slight body weight gain relative to the control diet.

\section{References}

Akakabe Y., Tamura Y., Iwamoto S., Takabayashi M., Nyuugaku T., 2006. Volatile organic compounds with characteristic odor in bamboo vinegar. Biosci. Biotechnol. Biochem. 70, 2797-2799

Aziz N.H., Farag S.E., Mousa L.A., Abo-Zaid M.A., 1998. Comparative antibacterial and antifungal effects of some phenolic compounds. Microbios 93, 43-54

Carlisle E.M., Berger J.W., Alpenfels W.F., 1981. A silicon requirement for prolyl hydroxylase activity. Fed. Proc. 40, 886

Choct M., 2009. Managing gut health through nutrition. Brit. Poultry Sci. 50, 9-15

Chu G.M., Jung C.K., Kim H.Y et al., 2013. Effects of bamboo charcoal and bamboo vinegar as antibiotic alternatives on growth performance, immune responses and fecal microflora population in fattening pigs. Anim. Sci. 84, 113-120

Dhawale A., 2005. Better eggshell quality with a gut acidifier. Poultry Int. 44, 18-21

Elliot M.A., Edward H.M., 1991. Effect of dietary silicon on growth and skeletal development in chickens. J. Nutr. 121, 201-207

Gilmore M.S., Ferretti J.J., 2003. The thin line between gut commensal and pathogen. Science 299, 1999-2002

Jiang X.L., 2005. An experiment on the sterilization effects of bamboo vinegar. J. Bamboo Res. 24, 50-53

Kimura Y., Suto S., Tatsuka M., 2002. Evaluation of carcinogenic/cocarcinogenic activity of chikusaku-eki, a bamboo charcoal by-product used as a folk remedy, in BALB/c 3T3 cells. Biol. Pharm. Bull. 25, 1026-1029

Lauronen J., Pakarinen M.P., Kuusanmakai P., Savilahti E., Vento P., Paavonen T., Halttunen J., 1998. Intestinal adaptation after massive proximal small-bowel resection in the pig. Scand. J. Gastroenterol. 33, 152-158 
Lutz T., Scharrer E., 1991. Effect of short-chain fatty acids on calcium absorption by the rat colon. Exp. Physiol. 76, 615-618

McDowell L.R., 1992. Minerals in Animal and Human Nutrition. Academic Press. San Diego, California, pp. 407-441

Noy Y., Sklan D., 1995. Digestion and absorption in the young chick. Poultry Sci. 74, 366-373

Partanen K.H., Mroz Z., 1999. Organic acids for performance enhancement in pig diets. Nutr. Res. Rev. 12, 117-145

Ruttanavut J., Matsumoto Y., Yamauchi K., 2012. A fluorescencebased demonstration of intestinal villi and epithelial cell in chickens fed dietary silicic acid powder including bamboo vinegar compound liquid. Histol. Histopathol. 27, 1333-1342

Samanta S., Haldar S., Ghosh T.K., 2010. Comparative efficacy of an organic acid blend and bacitracin methylene disalicylate as growth promoters in broiler chickens: effects on performance, gut histology and small intestinal milieu. Vet. Med. Int. 1-8, doi:10.4061/2010/645150

Sorrells K.M., Speck M.L., 1970. Inhibition of Salmonella gallinarum by culture filtrates of Leuconostoc citrovorum. J. Dairy Sci. $53,239-241$
Velmurugan N., Chun S.S., Han S.S., Lee Y.S., 2009. Characterization of chikusaku-eki and mokusaku-eki and its inhibitory effect on sapstaining fungal growth in laboratory scale. Int. J. Environ. Sci. Technol. 6, 13-22

Viveros A., Chamorro S., Pizarro M., Arija I., Centeno C., Brenes A., 2011. Effects of dietary polyphenol-rich grape products on intestinal microflora and gut morphology in broiler chicks. Poultry Sci. 90, 566-578

Wang H.F., Wang J.L., Zhang W.M., Liu J.X., Dai B., 2012. Effect of bamboo vinegar as an antibiotic alternative on growth performance and fecal bacterial communities of weaned piglets. Livest. Sci. 144, 173-180

Watarai S., Tana S., 2005. Eliminating the carriage of Salmonella enterica serovar Enteritidis in domestic fowls by feeding activated charcoal from bark containing wood vinegar liquid (Nekka-rich). Poultry Sci. 84, 515-521

Yamauchi K., 2007. Review of a histological intestinal approach to assessing the intestinal function in chickens and pigs. Anim. Sci. $78,356-370$ 